\title{
Mario Bunge and the Current Revival of Causal Realism
}

\section{Ingthorsson, Rögnvaldur D.}

Springer Verlag

2019

Ingthorsson , R D 2019 , Mario Bunge and the Current Revival of Causal Realism . in M R

Matthews (ed.) , Mario Bunge : A Centenary Festschrift . Springer Verlag , pp. 205-217 . https://doi.org/10.1007/978

http://hdl.handle.net/10138/339296

https://doi.org/10.1007/978-3-030-16673-1_12

acceptedVersion

Downloaded from Helda, University of Helsinki institutional repository.

This is an electronic reprint of the original article.

This reprint may differ from the original in pagination and typographic detail.

Please cite the original version. 
Author's preprint. Published in Matthews, Michael R. (Ed.) (2019). Mario Bunge: A Centenary Festschrift, Springer, pp. 205-18.

\section{Mario Bunge and the Current Revival of Causal Realism ${ }^{1}$}

\section{Rögnvaldur D. Ingthorsson ${ }^{2}$}

Abstract. Mario Bunge's Causality and Modern Science is arguably one of the best treatments of the causal realist tradition ever to have been written, one that defends the place of causality as a category in the conceptual framework of modern science. And yet in the current revival of causal realism in contemporary metaphysics, there is very little awareness of Bunge's work. This paper seeks to remedy this, by highlighting one particular criticism Bunge levels at the Aristotelian view of causation and illustrating its relevance for contemporary powers-based accounts. Roughly, the Aristotelian view depicts interactions between objects as involving a unidirectional exertion of influence of one object upon another. This idea of unidirectional action is central to the Aristotelian distinction between active and passive powers, and its corresponding distinction between active and passive objects. As Bunge points out, modern physics does not recognise the existence of any unidirectional actions at all; all influence comes in the form of reciprocal action, or interaction. If this is right, all notions deriving from or influenced by the idea of unidirectional actions - such as the concept of mutual manifestation and reciprocal disposition partners — risk being false by the same measure. Bunge drew the conclusion that the Aristotelian view is ontologically inadequate, but still advocated its use as the most useful approximation available in science. He considered, but ultimately rejected the possibility of a modified view of causation built on reciprocal action, because, in his view, it couldn't account for the productivity of causation. Bunge's critique of this particular aspect of the Aristotelian view cannot be overlooked in contemporary metaphysics, but it is possible to construe a modified view of causation that takes the reciprocity of interactions seriously without loss of productivity.

\section{Introduction}

In another contribution to this volume, Ingvar Johansson expresses puzzlement about the lack of awareness among philosophers of science about Mario Bunge's views about mechanisms and approximate truth. In this paper the focus is on another puzzle, the lack of awareness among contemporary metaphysicians about Bunge's views on causality. The particular concern is with those engaged in the revival of Aristotelian causal realism, now in the form of what is typically labelled powers-based accounts of causation. Proponents of powers-based accounts seem not to be aware of Bunge's critique of the Aristotelian view of causation, and therefore arguably continue to build on a flawed conception of causal influence, one that is incompatible with the theories and findings of modern science.

The $21^{\text {st }}$ Century has seen a dramatic revival of realist approaches in metaphysics. An important part of this revival is the re-examination of the relevance of Aristotelian metaphysics,

\footnotetext{
${ }^{1}$ This paper is based on research in the project "Scientific Essentialism: Modernising the Aristotelian View", funded 2015-2018 by Riksbankens Jubileumsfond: Swedish Foundation for Humanities and Social Sciences, Grant-ID: P14-0822:1.

${ }^{2}$ Department of Philosophy, Lund University, Sweden

Email: rognvaldur.ingthorsson@fil.lu.se
} 
often, but not always, with the aim of construing a scientifically informed account of causation. ${ }^{3}$ A focal point in this re-examination is the notion of powers - the idea that natural properties are best understood as determinate ways an object can affect other objects and be affected by them - and how this notion might help to elucidate causation, as well as other notions not discussed here, such as laws of nature, natural kinds, and agency.

While $21^{\text {st }}$ Century realists reach back to $20^{\text {th }}$ Century thinkers like Roy Bhaskar (1975), Rom Harré and Edward Madden (1975), as well as Nancy Cartwright (1989), they hardly ever mention Mario Bunge's Causality and Modern Science (1959/1979). ${ }^{4}$ Notable exceptions are Johansson (1989) and Ingthorsson (2002). This is unfortunate. Bunge is one of the very few to have noted that the Aristotelian view of causality - which Bunge calls the 'strict doctrine of causality' - is in one particular respect falsified by the theories and findings of empirical science. Roughly, the Aristotelian view depicts interactions between powerful particulars as involving a unidirectional exertion of influence of one object (the Agent) upon another (the Patient) which then results in a change in the Patient. Consequently, a cause on the Aristotelian view consists in an action of an Agent upon a Patient, and an effect is the change produced in the Patient. Modern science, on the other hand, does not recognise the existence of any unidirectional actions at all. It insists that all influence comes in the form of perfectly reciprocal action, or interaction, between two objects that subsequently both suffer a change. ${ }^{5}$ Indeed, Bunge drew the conclusion that the Aristotelian distinction between active and passive powers, and between Agents and Patients, is ontologically inadequate. If this is right, then in so far as modern powers-based accounts are influenced by the Aristotelian ideas about unidirectional influence, they risk being false by the same measure.

Bunge still advocated the Aristotelian view as the most anthropocentrically useful approximation of causality available in science. He considered, but dismissed, the possibility that causality could be modelled instead on the basis of reciprocal action. I think Bunge's critique of the Aristotelian view is conclusive and cannot be overlooked in contemporary metaphysics. On the other hand, I think Bunge is wrong to dismiss the possibility of a conception of causality as a phenomenon grounded in reciprocal action. In my previous works (Ingthorsson 2002, 2007), I have tried to modify the Aristotelian view to accommodate the reciprocity of interactions and to arrive at an ontologically adequate characterisation of causation that retains most of the characteristics Bunge thought were essential to causality, notably production and asymmetry. However, in that early work no effort was made to relate to the development of neo-Aristotelian powers-based accounts. This will be done here.

\section{The Aristotelian View of Causation}

Causal realism - in its most general form - is the view that causation is an objective feature of the world and not only a feature of our thinking (see, for instance, Bunge 1979, ch.1.1.2; Price 2001, p.106; Esfeld 2011). There are many philosophers who endorse causal realism in that general sense, but fewer who explicitly attempt to characterise it in greater detail. Those who do

\footnotetext{
${ }^{3}$ See, for instance, Ellis (2001), Ingthorsson (2002; 2007), Molnar (2003), Heil (2003 \& 2012), Lowe (2006), Bird (2007), Martin (2008), Marmodoro (2007; 2017), Mumford and Anjum (2011), and Jacobs (2011).

${ }^{4}$ First published 1959 as Causality: The Place of the Causal Principle in Modern Science, but references in this paper are to the 1979 edition.

${ }^{5}$ The fact that all interactions are perfectly reciprocal is universally acknowledged in the sciences and is impressed on students already in primary education. To verify, consult any undergraduate textbook in physics, such as Resnick, Halliday, \& Krane (2002).
} 
Author's preprint. Published in Matthews, Michael R. (Ed.) (2019). Mario Bunge: A Centenary Festschrift, Springer, pp. 205-18.

attempt such a characterisation tend to include some stance on most (if not all) of the following characteristics: necessity, production, efficiency, uniformity, and process. ${ }^{6}$ The affinity that their characterisations have with the older Aristotelian tradition is obvious, even if not always explicit. Modern characterisations of causal realism where the connection to the Aristotelian view is made explicit have appeared regularly throughout the $20^{\text {th }}$ Century, for instance in the works of W.E. Johnson (1924), Bunge (1979, ch.2), Dorothy Emmett (1985), Johansson (1989, ch.12), and Craig Dilworth (1996). But these works appear before the current Aristotelian revival and for some reason are rarely mentioned in the current literature on powers-based causation. The causal realist view that emerges in these writings is that new states of affairs are brought into existence when an already existing material body, or complex of bodies, changes due to an external influence without which the change would not have occurred and the new state of affairs never have existed; a view that echoes the spirit of Aristotle's claim that "everything that comes to be comes to be by the agency of something and from something and comes to be something" (Metaphysics, bk.7, 7, 1032a13). Typically, the external influence, or cause, is depicted in terms of an extrinsic motive agent (or simply Agent), which is an object possessing the power to influence other objects and which actually does act upon another object, an object sometimes referred to by the term Patient since it lacks a similar active power but is instead able to passively receive the influence exerted by an Agent and change in some particular way. Accordingly, a cause is the action of some object upon another object, and an effect is the change produced in the object acted upon; or, in other words, a cause is the exertion of influence by an Agent upon a Patient and an effect is the resulting change in the Patient.

Embedded in the presuppositional depth-structure of this view are three fundamental convictions about natural reality that continue to be implicitly assumed but are seldom brought out explicitly. Among the very few to explicitly discuss them are Bunge and Craig Dilworth. First is the belief that nothing comes into being out of nothing or passes into nothing. Dilworth calls it the principle of (the perpetuity of) substance (Dilworth 1996, p.53), while Bunge prefers the term genetic principle (1979, p.24). The latter label captures very well the core idea at play here, notably that everything has a natural origin; everything comes to be out of something already existing and due to the influence of something existing.

Second is the conviction that causal changes come about as the result of an influence being exerted by something on something else. I call it the principle of action, which is my own term for what I consider to be the proper causal realist take on what is usually called the causal principle (Bunge 1979, p.26), or the principle of causality (Dilworth 1996, p.57). The most watered-down form of the causal principle is 'there is a cause for everything', which leaves it entirely open what can count as a cause; even Humean regularity can fit the bill. However, in the causal realist tradition it is without doubt the exertion of influence that is meant to distinguish causal from non-causal changes of various kinds, say, inertial motion or spontaneous decay (for discussion of other kinds of determinations, see Bunge 1979, p.17ff).

Third is the conviction that the world changes in regular and determinate ways. This is often taken to be equivalent to the belief that the world behaves in accordance to natural laws, which is why Bunge calls it the principle of lawfulness (Bunge 1979, p.26), but others call it the principle of the uniformity of nature (Dilworth 1996, p.55). The principle does not entail a commitment to the existence of some kind of abstract entities, the laws, which somehow rule the behaviour of concrete entities. The principle is equally compatible with the idea - explicitly

\footnotetext{
${ }^{6}$ See, for instance, Bunge (1979, ch. 1), Ingthorsson (2002), Huemer \& Kovitz (2003), Chakravartty (2005), Marmodoro (2007), Esfeld (2011), and Mumford \& Anjum (2011).
} 
Author's preprint. Published in Matthews, Michael R. (Ed.) (2019). Mario Bunge: A Centenary Festschrift, Springer, pp. 205-18.

incorporated into the Aristotelian view - that objects behave in what Bunge calls 'immanent patterns of being and becoming' in virtue of their intrinsic and universal properties, patterns that can be expressed in the highly generalised form of law-statements (Bunge 1979, p.249).

In other words, the principle is equally compatible with immanent realism and powersbased metaphysics, as it is with Platonism about laws. Indeed, when Stephen Mumford insists there are no laws, what he means to say is that whatever uniformity there is in nature (and he believes it to be imperfect and therefore strictly speaking lawless) it is determined by the intrinsic powers of the particulars and not by general laws that directly rule the behaviour of the particulars, or indirectly by determining the causal role of the powers that the particulars bear (Mumford 2005). Anyhow, these three principles are part of the metaphysical framework of the Aristotelian view.

There are three salient features of the Aristotelian view that I would like to particularly emphasize. First, that it depicts causal influence as something that is exerted between substances, i.e. by an Agent on a Patient. In other words, the Aristotelian view depicts actions as occurring between persistent objects, not between events or states. This is contrary to what is the received view today, notably that causal influence is a relation between events or states. On the Aristotelian view, the states and events are always outcomes of an interaction between objects. As I have pointed out before (Ingthorsson 2002) this means that on the Aristotelian view, causal relations (between cause and effect) are not themselves productive, but are the products of something more fundamental, notably the interaction between powerful particulars. Second, that the Aristotelian view depicts the exertion of influence as being unidirectional; it goes from Agent to Patient. Third, that it does not depict effects as the product of the action of the agent alone, but of the sum total of material, formal and efficient causes; the effect is depicted as the product of the way two or more material objects act on each other in virtue of their powers to produce a change in those very objects. In Hobbes' words, "the efficient and material causes are both but partial causes, or parts of that cause, which in the next precedent article I called an entire cause" (1656, ch.IX, 4). It is this interaction between Agent and Patient that I identify with a process of production, and which we should consider to be the proper referent of the term 'causation'.

\section{Bunge's Critique of the Aristotelian View}

It is not feasible to recount here in full Bunge's discussion of the faults of the Aristotelian view. Interested readers should consult Causality and Modern Science, in particular Chapter 6. But the gist of it is that modern science flatly contradicts the Aristotelian assumption that influence is exerted unidirectionally between objects; and insists instead that all influence comes in the form of reciprocal action. The most accessible treatment of the concept of reciprocal action in physics is the one found in classical mechanics, and yet it requires something of a shift of perspective to get a full grasp of the concept. The claim 'for every action an equal and opposite reaction' is familiar enough, but it is often misunderstood to mean that effects react back on the cause, making cause and effect interdependent, or as saying that cause and effect are simultaneous (which is arguably the idea Kant labours with in the second analogy of experience; Kant 1787 , A189/B233).

The assumption is that 'action' and 'reaction' denote two different phenomena, of which the action has some form of ontological priority over the reaction; i.e. that the action provokes the reaction. This is such a common misunderstanding that every textbook on classical 
mechanics has to address this issue to imprint on the novice student a different, and correct, understanding.

We are not talking about the sense in which two lovers reciprocate feelings, nor the way we talk about human communication as reciprocal, nor the mutuality involved in the joint contribution of an active and passive power in the production of a change in the patient. No, action and reaction, or force and counterforce as they are also called, are reciprocal in the sense that they occur simultaneously in opposite directions, are of equal magnitude and of the same kind, and that therefore we really cannot objectively identify either of them as ontologically prior to the other; we are therefore as Heinrich Hertz observes "free to consider either of them as the force or the counterforce" (Hertz 1956, p.185).

The correct understanding of reciprocal action is that it isn't composed of two different kinds of actions, of which one gives rise to or provokes the other, but of mutual influence of the same kind occurring simultaneously between two objects. Bunge sums the point up by saying that "physical action and reaction are, then, two aspects of a single phenomenon of reciprocal action" (1979, p.153). In an interaction, so understood, neither side of the interaction has priority, and the terms 'action' and 'reaction' really are labels that can be used arbitrarily for either side. The point comes out very nicely in the following passage by James Clerk Maxwell:

The mutual action between two portions of matter receives different names according to the aspect under which it is studied, and this aspect depends on the extent of the material system which forms the subject of our attention. If we take into account the whole phenomenon of the action between the two portions of matter, we call it Stress [...] But if [...] we confine our attention to one of the portions of matter, we see, as it were, only one side of the transactionnamely, that which affects the portion of matter under our consideration - and we call this aspect of the phenomenon, with reference to its effect, an External Force acting on that portion of matter. The other aspect of the stress is called the Reaction on the other portion of matter (Maxwell 1877, pp.26-7)

The exact sense of the reciprocity of interactions is perhaps most clearly expressed in Newton's third law of motion which says that the force by which object 1 acts on object 2 is equal to the oppositely directed force by which object 2 acts on object $1\left(F_{\text {lon } 2}=-F_{2 o n 1}\right)$. Taking into account that the designations ' $F$ ' and ' $-F$ ', as well as 'object 1 ' and 'object 2 ' are assigned arbitrarily to the forces and objects involved, then the proper understanding of the reciprocity of interaction is that the influence exerted mutually between two objects is always of the same quantity, of the same kind, and occurs simultaneously in opposite directions, which is why we are unable to assign causal priority to one or the other. The only thing we can do, as Maxwell observed, is to assign explanatory priority, but then only on the basis of our subjective interests. In an interaction between a baseball and a window, we are as a general rule more concerned about what happens to the window than what happens to the ball. We therefore attend to the influence of the ball on the window, and the resulting change in the window, conveniently neglecting the influence exerted by the window on the ball and the resulting change in the state of motion of the ball.

Bunge is one of the very few to have noted that the fact that interactions are in reality perfectly reciprocal in this sense, is a serious threat to the Aristotelian view. It entails that "the polarization of interaction into cause and effect, and the correlative polarization of interacting objects into agents and patients, is ontologically inadequate" (Bunge 1979, pp.170-1). The reciprocity between interacting objects shows that there are no strictly passive substances, i.e. 
Author's preprint. Published in Matthews, Michael R. (Ed.) (2019). Mario Bunge: A Centenary Festschrift, Springer, pp. 205-18.

substances who only receive influence but do not themselves influence other things, nor are there substances who influence other things without being themselves affected in any way. Let us now examine how Bunge's finding affects contemporary powers-based accounts of causation.

\section{Powers-Based Accounts of Causality in the $21^{\text {st }}$ Century}

Powers-based accounts come in many different forms, but there is a growing consensus around a couple of core ideas. One idea, often traced back to C.B. Martin (1997) even though it has also been expressed by Bhaskar (1975, p.99) and Johansson (1989. p.164), is that individual powers never really bring about anything on their own, but only together with other powers. The term reciprocal dispositional partners (Martin 1997, pp.201-02) is now the favoured label used to denote the powers that jointly produce an outcome, and the term mutual manifestation is used to denote the outcome so produced (Martin 1997, p.202).

Despite widespread use of the terms mutual and reciprocal, the common assumption is still that interactions are unidirectional in the traditional Aristotelian way, i.e. that an active power of one object will partner up with a passive power of another object to jointly bring about a change in the object acted upon: a brick with the power to break will act upon a fragile window to break the window, and water with the power to dissolve will act upon soluble salt to dissolve the salt. Powers, on this view, operate mutually and/or reciprocally only in the sense that dispositional partners are equally important in bringing about the manifestation.

The neo-Aristotelian manner of talking about reciprocal disposition partners as pairs of active and passive powers that jointly bring about a mutual manifestation fits very naturally to our everyday conceptual scheme. We tend to think about what we can (and want to) achieve with our actions, and we rarely are interested in both sides of physical interactions. However, there is a clash with the conceptual framework of science. The clash comes out clearly if we compare the everyday and scientific understanding of the favourite examples used by friends of powers-based accounts, say, 'water dissolves salt'. On the powers-based, and everyday interpretation, water does something to salt that salt does not do to water; water dissolves salt, but salt does not dissolve water. However, is it correct to attribute to water as a unified body a simple power to being able to dissolve salt? If we ask science, the relevant power that makes water into a 'universal solvent' is actually the polarity of individual $\mathrm{H}_{2} \mathrm{O}$ molecules. It is this polarity that allows an $\mathrm{H}_{2} \mathrm{O}$ molecule to bind strongly to either the positively charged sodium ion $\left(\mathrm{Na}^{+}\right)$, or the negatively charged chloride ion $\left(\mathrm{Cl}^{-}\right)$and separate them from each other. Water is able to dissolve salt only as long as individual $\mathrm{H}_{2} \mathrm{O}$ molecules are able to bond with the components of individual $\mathrm{NaCl}$ molecules. In solid form, i.e. as ice, the water molecules are strongly bound to each other and therefore do not interact as easily with $\mathrm{NaCl}$. However, if you sprinkle salt on ice, it will to some extent melt the ice (depending on the temperature), and the resulting saline does not freeze as easily. Arguably, the effect salt has on ice is akin to the effect water has on salt; it dissolves it. The $\mathrm{NaCl}$ molecules interact with the $\mathrm{H}_{2} \mathrm{O}$ molecules in such a way as to break the bonds between $\mathrm{H}_{2} \mathrm{O}$ molecules and create bonds with $\mathrm{Na}^{+}$and $\mathrm{Cl}^{-}$instead, which in turn reduces the tendency of the $\mathrm{H}_{2} \mathrm{O}$ molecules to bond with each other to form solid ice.

The main point is that what appears in our everyday lives as something a certain amount of liquid does to solid grains of salt, without any apparent reciprocity, appears under the microscope of science as an aggregate of a multitude of perfectly reciprocal interactions between powerful particulars. At the very least, there is here an issue that hardly anybody has paid attention to, much because Mario Bunge's work on causality has for some reason come to be 
Author's preprint. Published in Matthews, Michael R. (Ed.) (2019). Mario Bunge: A Centenary Festschrift, Springer, pp. 205-18.

neglected. ${ }^{7}$

\section{Powerful Particulars or just Powers?}

Although contemporary powers-based accounts of causation have an obvious affinity with the older Aristotelian tradition, they also are clearly different. For one, they exclude final causes, which is actually a break with the older tradition that was already established by Hobbes (Hobbes 1656, ch.X, 7). Another difference is that today the objects bearing the powers play a less prominent role than they used to do. The assumption is that it is the powers that are causally efficacious, not the objects that have the powers, so much so that the object is all but neglected. As a result, contemporary neo-Aristotelians do not often talk in terms of interactions between objects. Notable exceptions to this trend are Ingthorsson (2002) and Marmodoro (2007, 2017). Instead the focus is entirely on powers jointly contributing to the manifestation of some or other outcome. So, for instance, the vectorial model suggested by Mumford and Anjum represents causation with the help of the conceptual construct of a 'quality space' in which various powers are represented as being present at a time and place and as mutually manifesting something, regardless of the objects that have them (Mumford \& Anjum 2011, ch. 2.3ff). The powers are presented as horizontal arrows emanating from a common vertical line, each pointing in opposite directions towards one or other outcome, $F$ or $G$ (Mumford \& Anjum 2011, ch. 2.3). There is nothing in the model that represents the objects that have the powers.

Even though the particulars bearing the powers disappear in the background, contemporary powers-based accounts still typically operate with the distinction between active and passive powers. On that view, causation is a phenomenon where active and passive powers jointly bring about a mutual manifestation; the heat of the fire and the ability of the hand to be heated results in the heating of the hand; the power of water to dissolve combines with the power of salt to dissolve to mutually manifest the dissolution of the salt. Indeed, the resulting image naturally gives rise to the problem of fit, notably why a particular active power only combines with some particular passive power to manifest an outcome; why don't they combine any which way (Williams 2010)?

Now, the shift in focus towards the causal primacy of the powers themselves, and away from the substances that have the powers, may in fact be traced back to Hobbes, but without making the object explanatorily redundant. He makes a point of stating that it isn't bodies qua bodies, that exert an influence on other bodies, but bodies qua so and so empowered (1656, ch.IX, 3). The fire doesn't heat because it is a body, but because it is hot. And yet Hobbes clearly depicts the power as something belonging to the object; it is the object that has the power to do to another object, and not the power that has the power to do to another power. Indeed, in the following statement from Locke it becomes abundantly clear that although objects act on each other in virtue of the powers, it is still the objects and not the powers that act:

Thus we say, fire has a power to melt gold, i.e. to destroy the consistency of its sensible parts, and consequently its hardness, and make it fluid; and gold has a power to be melted: that the Sun has a power to blanch wax, and wax a power to be blanched by the Sun, whereby the yellowness is destroyed, and whiteness made to exist in its room. (Locke 1689, bk. II, ch.xxi, 1)

To be explicit, the power to melt gold doesn't change the quality of hardness to become

\footnotetext{
${ }^{7}$ But see Johansson 1989 and Ingthorsson 2002).
} 
the quality of fluid; it is the fire that changes the gold from hard to fluid. The lesson to be learnt is that it is quite possible to accept that a body may not cause qua body but qua so and so empowered and yet retain the idea that it is the body that exerts the influence on other objects. Indeed, this is how Hobbes conceived of it:

A body is said to work upon or act, that is to say, do something to another body, when it either generates or destroys some accident in it: and the body in which an accident is generated or destroyed is said to suffer, that is, to have something done to it by another body; as when one body by putting forwards another body generates motion in it, it is called an AGENT; and the body in which motion is so generated, is called the PATIENT; so fire that warms the hand is the Agent, and the hand, which is warmed, is the Patient. That accident, which is generated in the Patient, is called the EFFECT (Hobbes 1656, ch.IX, 1).

We have then, on the one hand, the older account of physical causation in terms of interactions between powerful particulars, but one in which it is still assumed that influence is not reciprocal but unidirectional, and that in such interactions the active power of the Agent together with the passive power of the Patient jointly produce a change in the Patient. On the other hand, we have the more modern accounts, which merely talk about powers jointly manifesting some outcome, that outcome typically being the obtaining of some or other power. ${ }^{8}$

The main problem with a model of causation in terms of mutual manifestations without particulars is that it fails to connect explicitly to questions about the proper subject of change and to issues about persistence. To be sure, it represents different powers obtaining at different times, but says nothing about the object to which they belong, and which would then have changed through the interaction. Powers-based accounts that take objects rather than powers as the entities that act and are acted upon, have a definitive explanatory advantage in the field of metaphysics more generally.

\section{Bunge's Defence of Aristotelianism as a Useful Approximation}

While Bunge is one of the very few philosophers who have acknowledged and illustrated the ontological significance of the fact that physical interactions are reciprocal, he still resisted the possibility of constructing causality on the model of reciprocal action. On the one hand he thinks it is often possible to treat one side of an interaction as if it was the primary cause, without introducing significant errors, and on the other he thinks that a conception of causation in terms of reciprocal action would distort the concept of causation beyond recognisability. To be more precise, he thinks it would lead to a conception of causation in which we no longer have any asymmetry between cause and effect and in which causes do not produce effects. In total he has four objections:

- (i) Things are typically in a state of flux, and therefore actions are (usually) temporally prior to the reaction (a ball is in motion prior to its collision with a window).

\footnotetext{
${ }^{8}$ Ann Whittle has recently argued in favour of what she calls substance causation (2016), to which Andrei Buckareff has replied arguing in favour of powers causation (2017). Unfortunately, neither of them relates to Hobbes or Locke. I think their arguments reveal to some extent an assumption that there has to be a choice between the two, while Locke and Hobbes seem to advocate a view in which it is the unity of object/power that is the active ingredient of causation.
} 

Festschrift, Springer, pp. 205-18.

- (ii) Interactions are often so asymmetric that the reaction (and corresponding effect) can be quantitatively neglected (a stone falling to Earth has a negligible effect on the Earth's state of motion, even though in principle they act reciprocally on each other).

- (iii) Some processes, e.g. the spontaneous decay of particles, cannot be described as interactions (for instance the decay of a pion into a muon and neutrino).

- (iv) If actions do not produce reactions, then interaction does not involve productivity.

I have elsewhere dealt with these objections in detail (Ingthorsson 2002). Here I will mainly focus on (i) and (iv), and only briefly mention that (ii) isn't really an objection to the reciprocity of interactions, but rather a defence of the anthropocentric value of the Aristotelian view despite its shortcomings. The argument is that in many cases it involves no error at all to think of interactions as unidirectional even though they really are reciprocal, e.g. the interaction between a stone and the whole Earth. As Bunge writes:

Only if one of the masses is much smaller than the other (for example, a stone as compared with the whole Earth), can the greater mass be regarded as the cause of the acceleration of the smaller one, and the reaction of the latter's motion be quantitatively neglected [...i]n some cases this involves no error at all (Bunge 1979, pp.150-51).

I have two worries about (i). First, to treat the motion of the brick prior to the collision as an 'action' is arguably to confuse two distinct phenomena that are both called 'action' in classical mechanics: (i) the sum of the kinetic energy of an object over a period of time whether it is interacting with anything, and (ii) exertion of influence of an object $a$ on an object $b$. As Hertz observed, to use the term 'action' for the first phenomenon is likely to create confusion:

the name 'action' for the integral in the text has often been condemned as unsuitable [...] these names suggest conceptions which have nothing to do with the objects they denote [in mechanics, $R I]$. It is difficult to see how the summation of the energies existing at different times could yield anything else than a quantity for calculation [...] (Hertz 1956, p.228).

Arguably, before the ball actually comes into contact with a window, it does not 'act' in the second sense. That kind of action only begins on contact and then as one side of an interaction.

Second, modern physics denies there are absolute states of motion or rest. The window is therefore just as much in a state of motion as the brick and should therefore also count as being in a state of 'acting' (in the first sense) prior to their collision. Since everything is thus in flux prior to an interaction, flux does not give causal priority to anything in particular.

Bunge's fourth objection - that interactions do not involve production — is the most serious objection, but one that can be dealt with in a way that Bunge did not anticipate. Bunge's objection is built on the assumption that to model causation on reciprocal action commits us to treat 'action' as cause and 'reaction' as effect, and thus to construe causes and effects as standing in a perfectly symmetric and non-productive relation to each other: "Let us agree to call interactionism, or functionalism, the view according to which causes and effects must be treated on the same footing, in a symmetrical way excluding both predominant aspects and definitely genetic, hence irreversible, connections" (1979, p.162). This view, he claims, may be regarded as a "hasty extrapolation of the mechanical principle of the equality of the action and the reaction" (1979, p.162). I agree that what he calls 'interactionism' is a hasty extrapolation of this kind, but 
Author's preprint. Published in Matthews, Michael R. (Ed.) (2019). Mario Bunge: A Centenary Festschrift, Springer, pp. 205-18.

it is not how I propose to construe causation on the basis of reciprocal action (for a more detailed account, see Ingthorsson 2002).

There is no relation of one-sided existential dependence between action and reaction, rather a mutual dependence. But this only shows that reactions should not be construed as effects, and actions should not be construed as causes. The route to go is to accept that the Aristotelian view has been wrong to characterise causation in terms of Agents acting externally and unidirectionally on Patients. Instead we should accept, like Hobbes (1656, ch.IX, p.4) and later J.S. Mill (1843, p.217), that the only thing that does efficiently produce change is the interaction as a whole and that the entity that suffers a change is the compound whole of interacting things. In other words, interactions (not actions) are causes producing a certain outcome, which then counts as the effect. The relation between action and reaction is symmetrical, yes, but it does not follow from this that the relation between the interaction and the change it produces is symmetrical and non-productive. This is a possibility that Bunge does not consider.

\section{Conclusion}

The lesson to be learnt at the end of all this is that Bunge's critique of the Aristotelian view undermines the validity of central notions in contemporary powers-based accounts of causation. If interactions are genuinely reciprocal in the manner laid out above, then we should not conceive of powers-based causation in terms of active and passive powers jointly producing a mutual manifestation, one that only encompasses the change produced in the object possessing the passive power. That is a conception that arguably is anthropocentrically biased in the manner described by Maxwell. However, I have also argued that we should not think of Bunge's critique as a decisive refutation of the possibility of an account of causation in terms of reciprocal action between powerful particulars. Such interactions, as I have described them, can be conceived to involve production due to the exertion of influence (i.e. reciprocal action) such that the producer and product hold a relation of one-sided existential dependence, although this requires that we combine these components in a somewhat different way than before. It also fits certain widely accepted metaphysical principles, i.e. the genetic principle and the principle of lawfulness, but requires that the principle of action be substituted for what may be called the principle of reciprocity. This, I believe is however only a minor modification, and which serves to correct the Aristotelian view in light of advances in our best sciences.

\section{References}

Aristotle (1924). Aristotle's Metaphysics, W.D. Ross (ed.). Oxford: Clarendon Press.

Bhaskar, R. (1975). A Realist Theory of Science., London: Verson.

Bird, A. (2007). Nature's Metaphysics. Oxford: Clarendon Press.

Buckareff, A. A. (2017). A Critique of Substance Causation, Philosophia 45(3), pp.1019-26.

Bunge, M. (1979). Causality and Modern Science. Cambridge: Harvard University Press.

Cartwright, N. (1989). Nature's Capacities and Their Measurement. Oxford: Oxford University

Press.Chakravartty, A. (2005). Causal Realism: Events and Processes, Erkenntnis 63(1), $7-31$.

Dilworth, C. (1996). The Metaphysics of Science. Dordrecht: Klüwer Academic Publishers.

Emmet, D. (1985). The Effectiveness of Causes. Albancy NY: SUNY Press. 
Author's preprint. Published in Matthews, Michael R. (Ed.) (2019). Mario Bunge: A Centenary Festschrift, Springer, pp. 205-18.

Esfeld, M. (2011). Causal Realism, in D. Dieks, W. J. González, S. Hartman, and M. Stöltzner (eds.), Probabilities, Laws, and Structures (pp. 157-168). Dordrecht: Springer.

Harré, R. \& Madden, E. H. (1975). Causal Powers: A Theory of Natural Necessity. Oxford: Basil Blackwell.

Heil, J. (2003). From an Ontological Point of View. Oxford: Oxford University Press.

Heil, J. (2012). The Universe as We Find It. Oxford: Oxford University Press.

Hertz, H. (1956). The Principles of Mechanics. New York: Dover.

Hobbes, T. (1656/1839). Elements of Philosophy, Concerning Body. In W. Molesworth (ed.), The English Works of Thomas Hobbes of Malmesbury. London: Bohn.

Huemer, M. \& Kovitz, B. (2003). Causation as Simultaneous and Continuous, The Philosophical Quarterly, (53), 556-565.

Ingthorsson, R. D. (2002). Causal Production as Interaction, Metaphysica, 3(1), 87-119.

Ingthorsson, R. D. (2007). Is There a Problem of Action at a Temporal Distance? SATSNorthern European Journal of Philosophy, 8(1), 138-154.

Jacobs (2011) Powerful Qualities, Not Pure Powers. The Monist 94(1), 81-102.

Johansson, I. (1989). Ontological Investigations: An Inquiry into the Categories of Nature, Man, and Society. New York: Routledge.

Johnson, W. E. (1924). Logic, Part III: The Logical Foundations of Science. Cambridge: Cambridge University Press.

Kant I. (1787/1965). Critique of Pure Reason, N. Kemp Smith (trans.). New York: St. Martin's Press.

Locke, J. (1690/1996). An Essay Concerning Human Understanding, abridged and edited by K. P. Winkler. Indianapolis: Hackett,.

Lowe, E. (2006). The Four Category Ontology. Oxford: Oxford University Press.

Marmodoro, A. (2007). The Union of Cause and Effect in Aristotle: Physics 3.3, Oxford Studies in Ancient Philosophy (32) 205-232.

Marmodoro, A. (2017). Aristotelian Powers at Work: Reciprocity Without Symmetry in Causation, in J. Jacobs (ed.), Causal Powers (pp. 57-76). Oxford: Oxford University Press,

Martin, C.B. (1997). On the Need for Properties: The Road to Pythagoreanism and Back. Synthèse, 112, 193-231.

Martin, C.B. (2008). Mind in Nature., Oxford: Oxford University Press.

Maxwell, J.C. (1877). Matter and Motion. New York: Dover.

Mill, J.S. (1843/1974). A System of Logic, Ratiocinative and Inductive, Robson, J. M. (ed).

Toronto: Routledge \& Kegan Paul.

Molnar, G. (2003). Powers: A Study in Metaphysics.Oxford: Oxford University Press.

Mumford, S. (2005). Laws and Lawlessness. Synthèse 144(3), 397-413.

Mumford, S. \& Anjum, R. L. (2011). Getting Causes from Powers., Oxford: Oxford University Press.

Price, H. (2001). Causation in the Special Sciences: The Case for Pragmatism. In M. C. Galavotti, P. Suppes \& D. Costantini (eds.), Stochastic Causality (pp.103-21). Stanford: CSLI Publications,.

Resnick, R., Halliday, D., \& Krane, K. (2002). Physics, $5^{\text {th }}$ ed. New York: John Wiley \& Sons. Whittle, A. (2016). A Defence of Substance Causation. Journal of the American Philosophical Association 2(1), 1-20.

Williams, N. (2010). Puzzling Powers: The Problem of Fit. In A. Marmodoro (ed.), The 
Author's preprint. Published in Matthews, Michael R. (Ed.) (2019). Mario Bunge: A Centenary Festschrift, Springer, pp. 205-18.

Metaphysics of Powers: Their Grounding and Their Manifestations (pp.84-105). New York: Routledge. 